\title{
Low-Temperature Synthesis of Large-Area, Free-Standing Nanorod Arrays on ITO/Glass and other Conducting Substrates**
}

\author{
By Kevin P. Musselman, ${ }^{*}$ Gregory J. Mulholland, Adam P. Robinson, \\ Lukas Schmidt-Mende, ${ }^{*}$ and Judith L. MacManus-Driscoll*
}

Arrays of free standing nanorods or nanowires are of great interest for applications in data storage, catalysis, sensing, field emission, and optoelectronic devices. ${ }^{[1-4]}$ Hybrid solar cells, for example, attempt to combine nanostructured semiconducting metal oxides with organic semiconductors to produce efficient photovoltaics at low cost. An ideal architecture proposed for these cells consists of an array of semiconducting nanorods surrounded by a charge transporting polymer, where the interfacial distance is smaller than the exciton diffusion length in the polymer (approximately $10 \mathrm{~nm}$ ), resulting in efficient exciton separation at the interface. ${ }^{[4-6]}$ The development of such devices has so far been hindered by the inability to reliably produce nanostructures on appropriate substrates, including transparent conducting oxides and crystalline semiconductors. A general method is presented here for producing large area arrays of free standing nanorods on supporting substrates. The inclusion of titanium and tungsten adhesive layers has permitted the fabrication of anodic alumina thin film templates of unprecedented quality on indium tin oxide (ITO)/glass, silicon, and flexible substrates over $2 \mathrm{~cm}^{2}$ areas, of interest for devices. For the first time, free standing nanorods of a variety of oxides and metals have been reproducibly synthesized over large areas on ITO/glass substrates by electrochemical de position into the vertically aligned nanopores of the templates, followed by template removal.

A number of techniques have been used to fabricate nanorod arrays, including template synthesis, various forms of vapor deposition, chemical solution growth, electrochemical deposition, and sub micrometer lithography. ${ }^{[2,7]}$ Vapor deposi

[*] K. P. Musselman, Prof. J. L. MacManus Driscoll, G. J. Mulholland, Dr. A. P. Robinson

Department of Materials Science and Metallurgy University of Cambridge

Pembroke Street, Cambridge, CB2 3QZ (United Kingdom)

Email:kpdm2@cam.ac.uk; jld35@cam.ac.uk

Prof. L. Schmidt Mende

Department of Physics and Center for Nanoscience

Ludwig Maximilians University (LMU)

Amalienstr. 54, 80799 Munich (Germany)

[**] The authors gratefully acknowledge Dr. Yinglin Liu and Pedro Cuhna for helpful discussions regarding electrochemical depositions. We thank the Higher Education Funding Council for England (Overseas Research Studentship Scheme), Peterhouse, Cambridge (KPM), and the European Commission (Marie Curie Excellence Grant "NanoFen", MEXT CT 20040014156) for financial support. tion and lithographic methods are restricted by slow, expensive, high vacuum processes, and chemical solution ${ }^{[5]}$ and electrochemical ${ }^{[8,9]}$ growth of free standing arrays have largely been limited to certain materials, notably zinc oxide. A variety of oxide semiconductors have been proposed for use in nanostructured solar cells and many different metallic, semiconducting, and magnetic materials are of interest for data storage, sensing, catalysis and field emission devices, such that a more universal method is desirable.

The most versatile method for producing nanorods in the form of large area arrays has been the replication of patterns in templates, using filling methods such as pressure injection, electrochemical deposition, and capillary filling with sol gels. ${ }^{[7]}$ Electrodeposition, in particular, is advantageous for electronic applications as it ensures that there is electrical contact between the deposited nanorods and underlying electrode. It is a low temperature, inexpensive, scalable technique, which allows growth of a wide variety of metals and semiconduc tors. ${ }^{[2,10-12]}$ Both anodic aluminum oxide (AAO) and block copolymer ${ }^{[13]}$ templates can be produced with self assembling, vertically aligned pores over a large area for nanorod synthesis. Anodic alumina templates in particular have been well characterized since their introduction by Keller in 1953. ${ }^{[14-17]}$ They allow a greater range of pore sizes than the block copolymers and are more resistant to high temperature treatments. Nanoporous AAO, however, has primarily been produced using aluminum foils, such that nanorods and nanowires of various materials have been produced by electrochemical deposition onto a thin electrode layer on the bottom of the fragile, unsupported membrane. ${ }^{[2,18,19]}$

It is essential for device fabrication that templates be synthesized on supporting substrates, allowing them to be filled then etched away, leaving arrays of free standing, aligned nanorods of uniform diameter and length electrically con nected to a rigid substrate. Significant progress has been made in producing AAO templates on silicon substrates. ${ }^{[17,20]}$ Robinson et al., for example, have produced high quality AAO templates over large areas on silicon substrates and induced perfect pore ordering using focused ion beam pre patterning. ${ }^{[17]}$ The quality of nanorod arrays produced on silicon using these templates has also improved, although problems of non uniform filling of the nanopores and collapse of the nanorods after etching of the template remain. ${ }^{[21-23]}$ Silicon substrates are not suitable for many applications, and so 
AAO template synthesis on a variety of substrates should be demonstrated. For example, for optoelectronic applications, such as the hybrid solar cells discussed, the substrate must be transparent in order to transmit the majority of incident or emitted radiation and must have a conducting surface to act as an electrode. For these devices, transparent conducting oxide layers on glass substrates are commonly used.

Limited work has been done using conducting glass as a supporting substrate for AAO templates. Chu et al. ${ }^{[24-26]}$ produced AAO templates directly on conducting glass, but they did not report fabrication over large areas suitable for devices. Also, while some free standing nanorods were fabricated on the glass, the size and uniformity of the arrays was limited and the nanorods tended to collapse upon template removal. ${ }^{[26]}$ We present here, for the first time, a general technique for producing large area (greater than $1 \mathrm{~cm}^{2}$ ), free standing, size controlled nanorod arrays on conducting substrates, including conducting glass, by electrodeposition into high quality anodic alumina templates.

Factors previously limiting template synthesis on conducting substrates can be understood by examining the pore formation mechanism illustrated in Figure 1a c. Anodic alumina templates are formed by the anodization of an aluminum layer in an acidic electrolyte under constant voltage. Aluminum oxide is produced at the interface between the aluminum and its native oxide layer, as $\mathrm{O}^{2-}$ and $\mathrm{OH}^{-}$ions diffuse inwards through the oxide layer, and the oxide is dissolved at its outer interface with the acid. These interfacial reactions are accelerated at local regions of surface curvature (a)

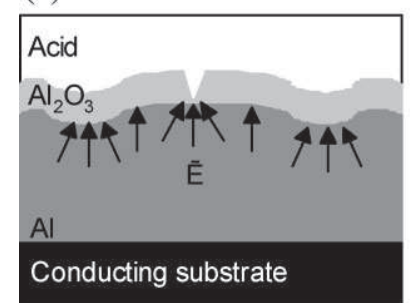

(c)

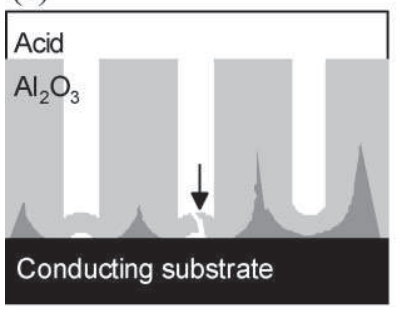

(b)

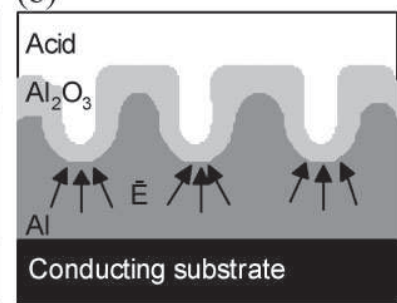

(d)

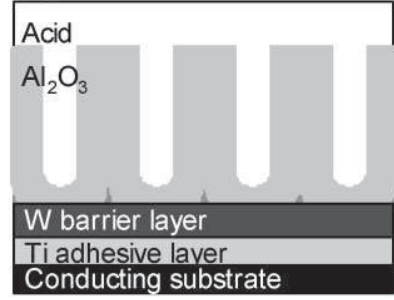

Figure 1. a c) Schematic diagram illustrating the pore formation mech anism in anodic alumina. a) Surface roughness and cracks in the oxide layer result in local field enhancements and the formation of nanopores. b) The pores progress through the aluminum film and tend towards an ordered hexagonal arrangement. c) Some pores reach the underlying substrate faster than others, which can result in delamination and crack formation. d) In this work, a W barrier was included to slow the anodization process, delaying delamination and cracking while all pores formed completely. (created by film roughness and cracks in the oxide layer) where there is an enhancement of the applied field, resulting in the formation of nanopores (Fig. 1a and b). The nanopores progress through the film until the aluminum is consumed, leaving an oxide layer at the bottom of the pores. It has been observed that when the pores reach the underlying substrate, the alumina at the bottom of the pores arches upwards, separating from the substrate (Fig. 1c). ${ }^{[20,21,24,27]}$ This weakens the connection between the template and substrate and can cause the template to become detached. Moreover, the formation of cracks in the oxide layer at the bottom of the pores has been observed at this stage of the anodization, as illustrated in Figure 1c. This exposes the underlying substrate to the electrolyte and may cause destructive gas evolution via electrolysis of the aqueous solution. ${ }^{[24]}$ In the case of ITO coated glass substrates, anodization of the ITO results in a dramatic increase in its sheet resistance ${ }^{[25]}$ and eventual dissolution. ${ }^{[24]}$

Ideally the anodization process could be stopped before cracking and delamination occurs. However, variations in the film thickness and field distribution invariably result in some pores reaching the substrate before others, as shown in Figure 1c. It is imperative that delamination and cracking of the oxide be delayed while slower growing pores are allowed to complete their formation. A titanium adhesive layer has successfully been incorporated to delay the detachment of templates from silicon substrates and to protect the silicon from exposure to the anodizing acid. ${ }^{[20,21]}$ Nevertheless, arching of the oxide layer was still observed, and the protective Ti layer has not been successfully applied to transparent conducting substrates.

In this work, an additional tungsten barrier layer has been incorporated between the $\mathrm{Al}$ and $\mathrm{Ti}$ (still included to improve adhesion), as illustrated in Figure 1d. Tungsten was selected because it anodizes much more slowly than Al. ${ }^{[28,29]}$ Therefore the $\mathrm{W}$ layer should slow the progress of the pores that reach it first, delaying unwanted delamination and crack formation while other pores complete their formation. The protection provided by this $\mathrm{W}$ barrier was found to make AAO template synthesis possible on a variety of supporting substrates, including conducting glasses.

A DC magnetron sputtering system was used to deposit the aluminum films and adhesive layers on supporting substrates. Approximately $5 \mathrm{~nm}$ of Ti and $550 \mathrm{~nm}$ of W were sputtered, followed by $100700 \mathrm{~nm}$ of Al. Sputtering powers and pressures specific to the system used were selected to produce smooth, stress free films (see experimental section). The deposition of stress free Ti, W, and Al layers was found to be crucial for preventing template delamination during the anodization process. While the $\mathrm{Ti}$ and $\mathrm{W}$ layers were deposited at room temperature, the sputtering chamber was cooled with liquid nitrogen for $23 \mathrm{~h}$ before sputtering the $\mathrm{Al}$ films in order to reduce the surface roughness and hence improve the uniformity of the anodization. The Al films were anodized in oxalic acid $(0.3 \mathrm{M})$ at a constant voltage of $40 \mathrm{~V}$. This voltage is known to maximize the hexagonal ordering of the pores and 
produces a hole periodicity of $100 \mathrm{~nm} \cdot{ }^{[17]}$ Following anodiza tion, a pore widening step was used to vary the diameter of the pores. The templates were soaked in a phosphoric acid solution $(5 \%)$ at room temperature for periods ranging from 1590 minutes. This step also served to remove the oxide layer formed at the bottom of the pores during anodization.

The tungsten barrier layer was found to dramatically improve the quality of AAO templates synthesized on supporting substrates, including transparent conducting oxi des. High quality templates were produced on ITO/glass and silicon substrates, with no defects visible over typical $2 \mathrm{~cm}^{2}$ substrate areas. Preliminary attempts were also successful on ITO coated flexible polyimide substrates, demonstrating the versatility of this method (the ability to produce nanorod arrays on thin, flexible substrates will be of great interest for many applications). Defect free templates were produced for all $\mathrm{W}$ and $\mathrm{Al}$ thicknesses examined. A $5 \mathrm{~nm} \mathrm{~W}$ barrier was employed for the remainder of this work to maximize the optical transparency of the adhesive layers. Scanning electron microscopy (SEM) cross sections revealed that templates approximately $800 \mathrm{~nm}$ thick were produced from $500 \mathrm{~nm}$ thick $\mathrm{Al}$ films. The greater thickness is as a result of volume expansion by the anodization. Figure 2 shows a SEM image of an AAO template that was anodized from a $150 \mathrm{~nm}$ thick $\mathrm{Al}$ film on an ITO/glass substrate and pore widened for 45 minutes. The pore periodicity matched the $100 \mathrm{~nm}$ value expected for these anodization conditions.

The high quality of the templates produced is seen in Figure 3, which shows an as anodized template on ITO/glass (right hand image) and a similar template after the electro deposition of $\mathrm{Cu}_{2} \mathrm{O}$ nanorods (left hand image). These very thin layers of $\mathrm{Ti}$ and $\mathrm{W}$ maintained a high optical transparency and were sufficient to prevent delamination of the templates during anodization. Attempts to fabricate similar templates on ITO/glass using only a Ti adhesive layer were unsuccessful, even when stress free films were employed and great care was taken to deposit a smooth, uniform $\mathrm{Al}$ film. Without the $\mathrm{W}$ barrier layer, delamination and cracking of the porous template was always observed prior to completion of the anodization process over the entire $\left(2 \mathrm{~cm}^{2}\right)$ substrate area. The

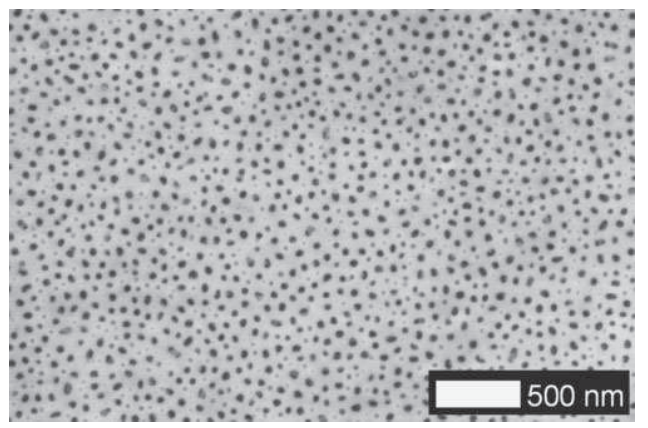

Figure 2. SEM image of an anodic alumina template formed on an ITO/ glass substrate (with $5 \mathrm{~nm} \mathrm{Ti}$ and $\mathrm{W}$ layers) by anodization in oxalic acid $(0.3 \mathrm{M})$ at $40 \mathrm{~V}$ and pore widening in phosphoric acid $(5 \%)$ for 45 minutes. The image is representative of all regions of the $2 \mathrm{~cm}^{2}$ substrate.

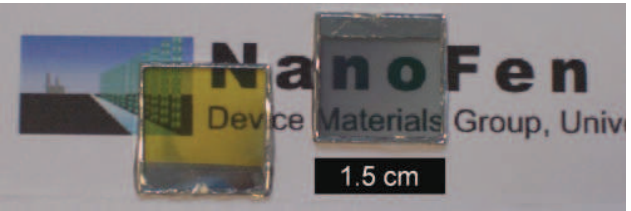

Figure 3. As anodized template (right) and template filled with $\mathrm{Cu}_{2} \mathrm{O}$ nanorods (left), both on commercial ITO/glass substrates. The template consists of $5 \mathrm{~nm} \mathrm{Ti}$ and $\mathrm{W}$ layers and a $800 \mathrm{~nm}$ thick porous AAO membrane.

thin W layer was extremely efficient at slowing the anodization process, permitting thorough anodizations where the slower forming pores could reach the underlying substrate without delamination of the film. In particular, the absence of defects indicates good pore formation at the bottom of the nanoscopic channels. Well formed pores at the substrate are essential to avoid non uniform filling of the template and the collapse of nanowires after template removal.

Identical templates on ITO/glass that were pore widened for various durations were statistically analyzed using ImageJ image analysis software to determine the relationship between pore widening time and pore diameter. The results are shown in Figure 4. A linear increase in pore diameter was observed, corresponding to approximately $0.43 \mathrm{~nm}$ per minute of exposure to phosphoric acid (5\%). As expected, this agrees with a previously reported value of $0.45 \mathrm{~nm}$ per minute for AAO on silicon, ${ }^{[17]}$ as the substrate type should have little influence on the etch rate. The initial pore size, on the other hand, differs significantly from that observed on silicon, as the substrate influences the field strength and distribution during anodization. Hence, while an average pore diameter of approximately $23 \mathrm{~nm}$ was observed on ITO/glass substrates prior to pore widening, an initial pore diameter of $36 \mathrm{~nm}$ was observed on silicon.

The templates displayed in Figures 24 exhibit pore densities of approximately $10^{10} \mathrm{~cm}^{-2}$. Using different acids

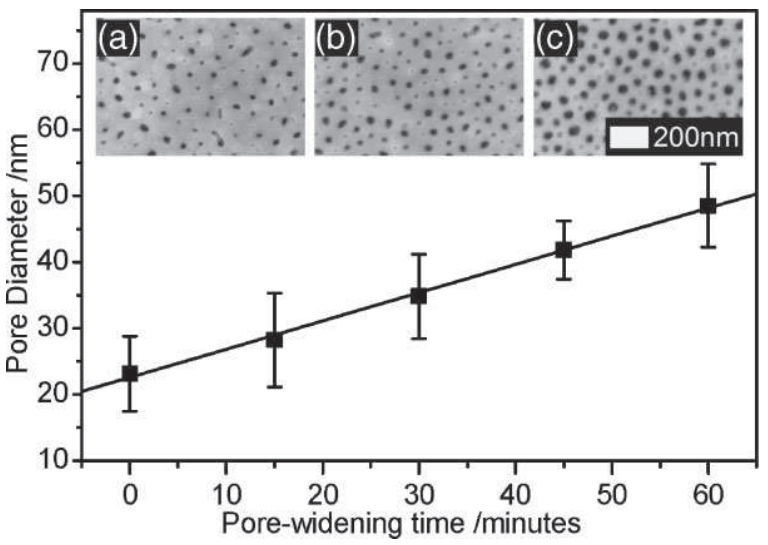

Figure 4. Average nanopore diameter as a function of pore widening time in phosphoric acid (5\%), for AAO templates on commercial ITO/glass substrates with $\mathrm{Ti}$ and $\mathrm{W}$ adhesive layers. Insets show SEM images of templates after a) 15 , b) 30 , and c) 60 minutes of pore widening. 
Table 1. Electrodeposition parameters for nanorod synthesis

\begin{tabular}{llc}
\hline Material & \multicolumn{1}{c}{ Deposition Solution } & Voltage vs. Ag/AgCl $[\mathrm{V}]$ \\
\hline $\mathrm{Cu}$ & $\mathrm{CuSO}_{4}(0.4 \mathrm{M})+$ lactic acid $(3 \mathrm{M})(\mathrm{pH}$ adjusted to 3 with $\mathrm{NaOH}(4 \mathrm{M}))$ & 0.4 \\
$\mathrm{Cu}_{2} \mathrm{O}$ & $\mathrm{CuSO}_{4}(0.4 \mathrm{M})+$ lactic acid $(3 \mathrm{M})(\mathrm{pH}$ adjusted to 12.5 with $\mathrm{NaOH}(4 \mathrm{M}))$ & 0.4 \\
$\mathrm{Ni}$ & $\mathrm{NiSO}_{4}(1 \mathrm{M})+\mathrm{H}_{3} \mathrm{BO}_{3}(0.5 \mathrm{M})$ & 21 \\
$\mathrm{TiO}_{2}$ & $\mathrm{TiCl}_{3}(10 \%)$ in $\mathrm{HCl}(20-30 \%)\left(\mathrm{pH}\right.$ adjusted to 2.7 with $\left.\mathrm{Na}_{2} \mathrm{CO}_{3}(1.9 \mathrm{M})\right)$ & 1.9 \\
\hline
\end{tabular}

and anodization voltages, pores have been produced in $\mathrm{Al}$ foils with diameters below $10 \mathrm{~nm}$ and densities above $10^{12} \mathrm{~cm}^{-2} \cdot{ }^{[7,30]}$ Hence, through control of anodization conditions and pore widening times, a large range of pore diameters and densities can be obtained for these nanopores and nanorod structures. The Al thin films produced here on supporting substrates are compatible with previously reported patterning techniques, ${ }^{[17,22,31]}$ such that perfectly ordered arrays of pores, and hence nanorods, with extremely narrow diameter distributions are possible.

Following pore widening, various metals and semiconduc tors were electrochemically deposited into the nanopores to produce arrays of nanorods. Potentiostatic electrodepositions of copper, copper(I) oxide, ${ }^{[12]}$ nickel, ${ }^{[11]}$ and titanium dioxide $^{[10]}$ were performed using a standard three electrode system in aqueous electrolytes of dissolved precursors, as summarized in Table 1. Similar solutions were used for the $\mathrm{Cu}$ and $\mathrm{Cu}_{2} \mathrm{O}$ depositions, the difference being the $\mathrm{pH}$ level, which was adjusted using a $\mathrm{NaOH}$ (4 M) solution. Wires that were predominantly $\mathrm{Cu}$ and $\mathrm{Cu}_{2} \mathrm{O}$ were produced at $\mathrm{pH}$ levels of 3 and 12.5 respectively, whereas composite nano wires containing both $\mathrm{Cu}$ and $\mathrm{Cu}_{2} \mathrm{O}$ were produced at intermediate $\mathrm{pH}$ levels. All nanowires were synthesized directly from solution, with the exception of $\mathrm{TiO}_{2}$, which required annealing at $450{ }^{\circ} \mathrm{C}$ in air for $4 \mathrm{~h}$ for crystallization. The depositions were con trolled using a computer, and the amount of charge collected at the working electrode was used to estimate the thickness of material deposited, permitting control of the nanorod length. Following electrochemical deposition, the AAO templates were removed by soaking the samples in a $\mathrm{NaOH}(0.12 \mathrm{~m})$ solution for periods ranging from 1560 minutes, depend ing on the template thickness.

Figure 5 displays SEM images of free standing a d) $\mathrm{Cu}_{2} \mathrm{O}$, e) $\left.\mathrm{Cu}, \mathrm{f}\right) \mathrm{TiO}_{2}$, and g) $\mathrm{Ni}$ nanorod arrays synthesized on ITO/glass substrates. The $\mathrm{Cu}_{2} \mathrm{O}$ nanorod arrays in Figure $5 \mathrm{a}$ and $\mathrm{b}$ were deposited in templates pore widened for 45 minutes and the arrays in Figure $5 \mathrm{c}$ and $\mathrm{d}$ were deposited in templates widened for 30 minutes. The ability to control nanorod diameters via the pore widening time is evident, as larger nanorods are observed for the samples pore widened for 45 minutes. Likewise, good control over nanorod length was demonstrated for $\mathrm{Cu}_{2} \mathrm{O}$ depositions. The nanorod knocked onto its side in Figure 5a has a length of several hundred nanometers, consistent with that estimated from the charge collected at the sample surface. The high quality of the nanostructures produced is emphasized in the lower magnification image of Figure $5 \mathrm{~b}$. The $36 \mu \mathrm{m}^{2}$ area is virtually free of any defects or collapsed wires, and is representative of the entire $2 \mathrm{~cm}^{2}$ sample area. This extremely uniform pore filling is a consequence of the quality of the AAO templates produced on the transparent conducting substrates.

Upper limitations were encountered for achievable free standing nanorod lengths, as cohesive forces between long nanorods caused them to bunch together during the template
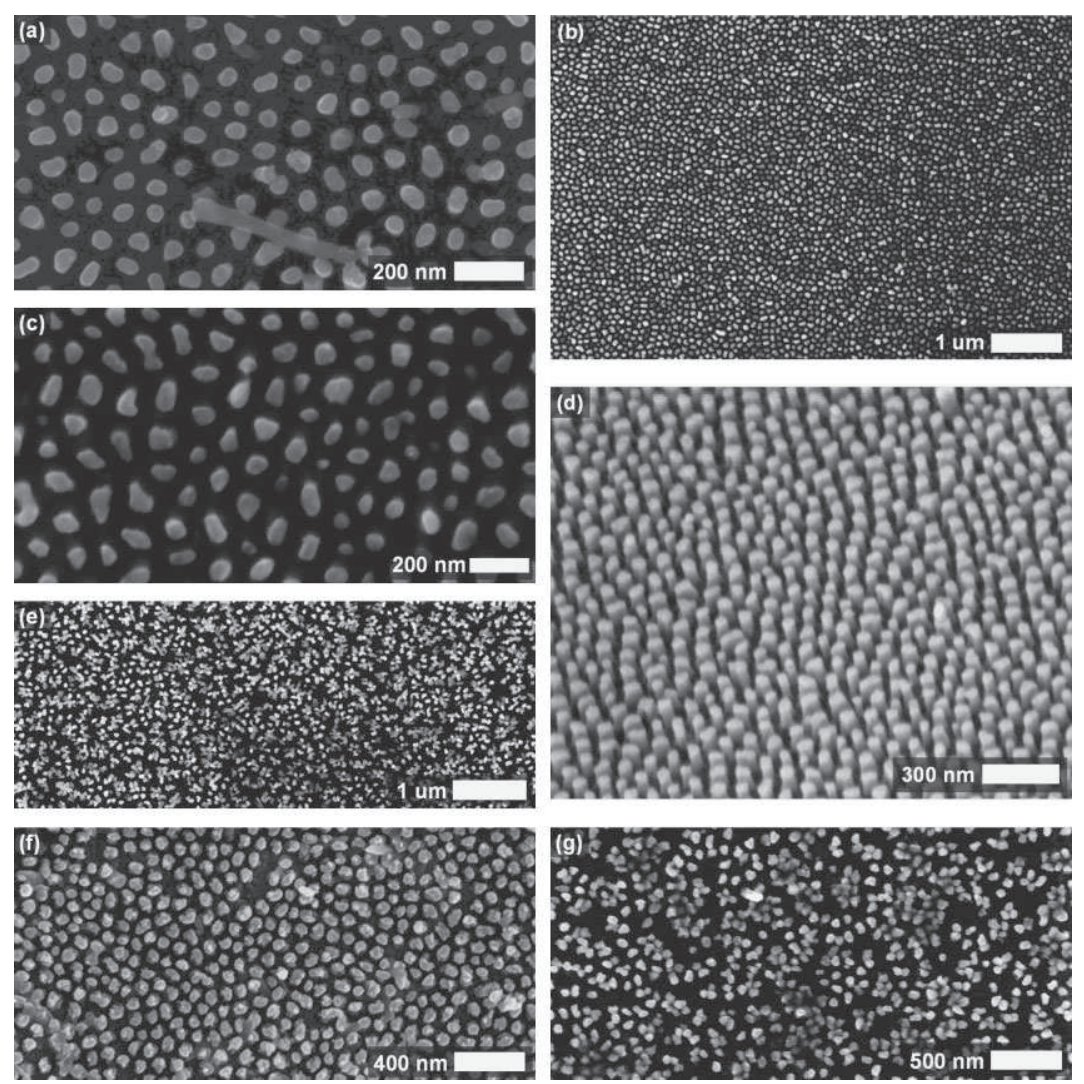

Figure 5. SEM images of free standing a d) $\mathrm{Cu} 2 \mathrm{O}$, e) $\mathrm{Cu}, \mathrm{f}$ ) $\mathrm{TiO} 2$, and g) Ni nanorod arrays on ITO/glass substrates. Arrays shown in a), b), and g) were produced in templates pore widened for 45 minutes, whereas the arrays shown in c d), e), and f) were pore widened for 30, 50, and 60 minutes, respectively. 
removal step. Some $\mathrm{Cu}$ nanorod bunching is observable in Figure $5 \mathrm{e}$, where the nanorods were approximately $300 \mathrm{~nm}$ long. The $\mathrm{Cu}_{2} \mathrm{O}, \mathrm{Cu}$, and $\mathrm{TiO}_{2}$ arrays all typically produced bunched nanorods for lengths greater than $300400 \mathrm{~nm}$, thus limiting the aspect ratio of free standing nanorods to a value below 10. In contrast, Ni nanorods exhibited bunching at much shorter lengths (Figure 5g), possibly due to attractive magnetic forces.

Figure 6 shows XRD measurements for free standing nanorod arrays produced on ITO/glass substrates. The relevant diffraction peaks aside from the ITO, Ti, W and Al background signals have been highlighted for clarity. It is impressive that with the exception of $\mathrm{TiO}_{2}$, which requires a high temperature annealing step at $450^{\circ} \mathrm{C}$, crystalline nanorod arrays can be directly synthesized using room or near room temperature electrochemical solutions. The structural properties of the nanorods naturally depend on the material type and the particular electrochemical deposition parameters used. Application of Scherrer's Equation to the diffraction peaks in Figure 6 reveals a crystallite size of approximately $15 \mathrm{~nm}$ for the $\mathrm{TiO}_{2}$ nanorods. The $\mathrm{Cu}_{2} \mathrm{O}$ nanorods, on the other hand, exhibit a crystallite size of approximately $55 \mathrm{~nm}$, possibly limited by the dimensions of the nanopores.

In using this technique, it is important to consider the presence of the thin Ti and W layers, as they may influence the electrical contact between the nanorods and substrate. Resistivity measurements were performed on $\mathrm{Cu}_{2} \mathrm{O}$ nanorod arrays synthesized on ITO/glass using the method presented

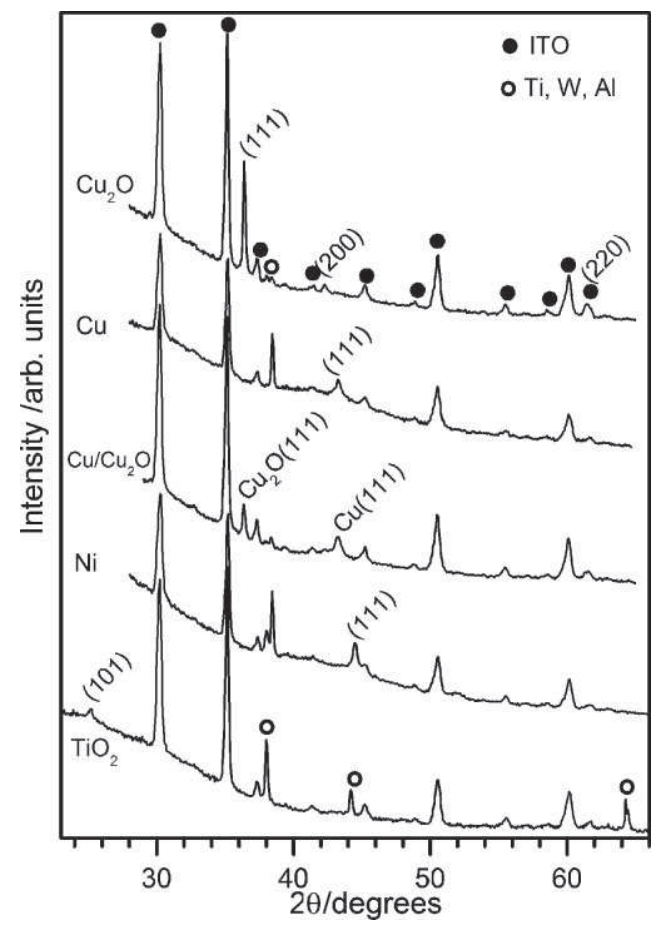

Figure 6. $\mathrm{X}$ ray diffraction measurements of free standing $\mathrm{Cu}_{2} \mathrm{O}, \mathrm{Cu}, \mathrm{Cu}$ / $\mathrm{Cu}_{2} \mathrm{O}$ composite, $\mathrm{Ni}$, and $\mathrm{TiO}_{2}$ nanorod arrays on ITO/glass after template removal. here and on bulk $\mathrm{Cu}_{2} \mathrm{O}$ films electrodeposited directly onto ITO/glass substrates. Similar Ohmic behavior was observed for both, attributable to the fact that ITO and W have similar work functions of $4.5 \mathrm{eV}^{[32]}$ and $4.55 \mathrm{eV}^{[33]}$ respectively. Good electrical contact was obtained between the $\mathrm{Cu}_{2} \mathrm{O}$ nanorods, thin Ti and W layers, and the underlying ITO substrate. Room temperature resistivities of $1.0 \times 10^{4} \Omega \mathrm{cm}$ were measured for both the nanorod arrays and bulk $\mathrm{Cu}_{2} \mathrm{O}$ films, similar to previously reported values for electrodeposited $\mathrm{Cu}_{2} \mathrm{O}$ films. ${ }^{[34]}$ However, for other conducting substrates and nanorod materials, the influence of the $5 \mathrm{~nm}$ Ti and $\mathrm{W}$ adhesive layers may be more pronounced and must be considered when synthesizing arrays for a particular application. Alternative adhesive layers with the same ability to slow the anodization process, but different electrical properties than $\mathrm{W}$, are an area for further investigation.

The ability to reproducibly synthesize high quality, free standing nanorod arrays by low temperature methods over large areas on supporting substrates represents significant progress towards the realization of many promising nano structured devices. The dramatic improvement in the quality of nanorod arrays produced on transparent conducting substrates in this work is a direct result of the synthesis of AAO templates of unprecedented quality and holds great promise for hybrid solar cells and other devices. The inclusion of a tungsten barrier layer was found to prevent delamination and cracking of anodic alumina membranes, permitting device quality nano porous templates to be fabricated on various conducting surfaces, including crystalline semiconductors, conducting glasses, and flexible substrates.

\section{Experimental}

DC Magnetron Sputtering: The ITO substrates (Praezisions Glas \& Optik) consisted of a $250 \mathrm{~nm}$ ITO layer (approximately $10 \Omega \mathrm{sq}^{1}$ ) on soda glass. The silicon substrates were n type (100) silicon. Preliminary flexible ITO substrates were fabricated by depositing approximately $20 \mathrm{~nm}$ of $\mathrm{Ti}$ (for adhesion) and $100 \mathrm{~nm}$ of ITO onto $20 \mu \mathrm{m}$ thick polyimide films using an Emitech sputter coater. The substrates were thoroughly cleaned in an ultrasonic bath with acetone and iso propanol for $2 \mathrm{~h}$ prior to loading in the sputtering system. The sputtering system was typically pumped to a pressure of $10^{7} \mathrm{mbar}$ or less. The Ti, $\mathrm{W}$, and $\mathrm{Al}$ layers were sputtered from $>99.5 \%,>99.5 \%$, and $99.999 \%$ purity targets, respectively, using an argon plasma. The Ti, W, and $\mathrm{Al}$ were sputtered at powers and argon pressures of approximately $15 \mathrm{~W}$, $30 \mathrm{~W}$, and $20 \mathrm{~W}$ and $3.0 \mathrm{~Pa}, 2.4 \mathrm{~Pa}$, and $0.5 \mathrm{~Pa}$ respectively to produce stress free films. Stress free conditions were identified by depositing test layers at various pressures on thin polyimide films $\left(4 \mathrm{~cm}^{2}, 12.5 \mu \mathrm{m}\right.$ thick) and observing film curvature. Typical sputtering times were $30 \mathrm{~s}$ and $15 \mathrm{~s}$ for the Ti and $\mathrm{W}$ layers, and $30 \mathrm{~min}$ for $500 \mathrm{~nm} \mathrm{Al} \mathrm{films.} \mathrm{The}$ sputtering chamber was cooled with liquid nitrogen for $23 \mathrm{~h}$ before sputtering the $\mathrm{Al}$ films in order to reduce the surface roughness and improve the uniformity of the anodization.

Anodization: A thin layer of crystal bond was applied to the edges of the sputtered $\mathrm{Al}$ films to prevent exposure to the electrolyte during anodization. An insulated wire was attached to the $\mathrm{Al}$ fim with $\mathrm{Ag}$ paste and masked with Kapton tape to provide an electrical connection. A Keithley 2400 SourceMeter supplied the constant voltage (40 V) for the anodizations and a $2.25 \mathrm{~cm}^{2}$ platinum counter electrode was immersed in the oxalic acid $(0.3 \mathrm{M})$ at room temperature, parallel to the 
Al film at a distance of $12 \mathrm{~cm}$. A LabVIEW program was used to monitor the anodization current and the transparency of the Al film was visually observed. As the pores reached the bottom of the Al, the film became transparent and the current decreased. The current leveled out when all of the pores reached the underlying adhesive layers, at which point the anodization was manually stopped.

Electrodepositions: The potentiostatic electrodepositions were performed using a Princeton Applied Research Model 363 Potentio stat/Galvanostat. The precursor concentrations, deposition voltages, and temperatures are summarized in Table 1 . The underlying substrates were electrically connected as before, with an insulated wire, Ag paste, and Kapton tape. For all depositions, a constant voltage was maintained relative to a $\mathrm{Ag} / \mathrm{AgCl}$ reference electrode in a saturated aqueous $\mathrm{KCl}$ solution, and a $2.25 \mathrm{~cm}^{2}$ platinum counter electrode was employed. For $\mathrm{TiO}_{2}$, nitrogen was bubbled through the solution for one hour prior to the deposition.

Structural Characterization: The nanorod arrays were examined using a LEO VP1530 field emission SEM, and a Bruker D8 theta/theta $\mathrm{X}$ ray diffraction (XRD) system with $\mathrm{Cu} \mathrm{K} \alpha$ radiation $\left(\begin{array}{ll}\lambda & 1.5418 \AA\end{array}\right)$ and a LynxEye position sensitive detector.

Resistivity Measurements: $\mathrm{Cu}_{2} \mathrm{O}$ was electrodeposited into a $800 \mathrm{~nm}$ thick template such that the wires reached the top of the pores (as observed by SEM). Gold contacts $\left(5.5 \mathrm{~mm}^{2}\right)$ were evaporated onto the template to contact the tops of the wires. Similarly, $2 \mu \mathrm{m}$ thick layers of $\mathrm{Cu}_{2} \mathrm{O}$ were electrodeposited onto bare ITO/glass substrates and $\mathrm{Au}$ contacts were evaporated on top. Electrical leads were attached to the $\mathrm{Au}$ contacts and underlying ITO contacts, and four wire resistivity measurements were performed using a Keithley 2400 SourceMeter under computer control.

[1] J. Mallet, K. Yu Zhang, S. Mátéfi Tempfli, M. Mátéfi Tempfli, L. Piraux, J. Phys. D: Appl. Phys. 2005, 38, 909.

[2] Y. Xia, P. Yang, Y. Sun, Y. Wu, B. Mayers, B. Gates, Y. Yin, F. Kim, H. Yan, Adv. Mater. 2003, 15, 353.

[3] C. Levy Clement, R. Tena Zaera, M. Ryan, A. Katty, G. Hodes, $A d v$. Mater. 2005, 17, 1512.

[4] G. K. Mor, K. Shankar, M. Paulose, O. K. Varghese, C. A. Grimes, Appl. Phys. Lett. 2007, 91, 152111.

[5] L. Schmidt Mende, J. MacManus Driscoll, Mater. Today 2007, 10, 40.

[6] A. Mayer, S. Scully, B. Hardin, M. Rowell, M. McGehee, Mater. Today 2007, 10, 28

[7] K. Shankar, A. Raychaudhuri, Mater. Sci. Eng. C 2005, 25, 738.
[8] M. Wong, A. Berenov, X. Qi, M. Kappers, Z. Barber, B. Illy, Z Lockman, M. Ryan, J. MacManus Driscoll, Nanotechnology 2003, 14, 968.

[9] J. Elias, R. Tena Zaera, C. Levy Clement, Thin Solid Films 2007, 515, 8553.

[10] L. Kavan, B. O’Regan, A. Kay, M. Gratzel, J. Electroanal. Chem. 1993, $346,291$.

[11] K. M. Yin, B. T. Lin, Surf. Coat. Tech. 1996, 78, 205.

[12] E. Ko, J. Choi, K. Okamoto, Y. Tak, J. Lee, ChemPhysChem 2006, 7, 1505.

[13] S. Kim, M. Misner, T. Xu, M. Kimura, T. Russell, Adv. Mater. 2004, 16 , 226.

[14] F. Keller, M. Hunter, D. Robinson, J. Electrochem. Soc. 1953, 100, 411

[15] H. Masuda, M. Satoh, Jpn. J. Appl. Phys. 1996, 35, L126.

[16] W. Lee, R. Ji, U. Gosele, K. Nielsch, Nat. Mat. 2006, 5, 741.

[17] A. Robinson, G. Burnell, M. Hu, J. MacManus Driscoll, Appl. Phys. Lett. 2007, 91, 143123

[18] A. J. Yin, J. Li, W. Jian, A. J. Bennett, J. M. Xu, Appl. Phys. Lett. 2001, 79, 1039.

[19] E. Herderick, J. Tresback, A. Vasiliev, N. Padture, Nanotechnology 2007, 18, 155204.

[20] M. Wu, I. Leu, M. Hon, J. Mater. Res. 2004, 19, 888.

[21] O. Rabin, P. Herz, Y. Lin, A. Akinwande, S. Cronin, M. Dresselhaus, Adv. Funct. Mater. 2003, 13, 631.

[22] A. Maria Chong, L. Tan, J. Deng, H. Gao, Adv. Func. Mater. 2007, 17, 1629.

[23] Y. Lee, I. Leu, M. Wu, J. Yen, K. Fung, J. Alloys Compd. 2007, 427, 213.

[24] S. Chu, K. Wada, S. Inoue, S. Todoroki, J. Electrochem. Soc. 2002, 149, B321.

[25] S. Chu, K. Wada, S. Inoue, S. Todoroki, Y. Takahashi, K. Hono, Chem. Mater. 2002, 14, 4595.

[26] S. Chu, K. Wada, S. Inoue, S. Todoroki, Electrochim. Acta 2003, 48, 3147.

[27] D. Crouse, Y. Lo, A. E. Miller, M. Crouse, Appl. Phys. Lett. 2000, 76 , 49

[28] N. Yasui, A. Imada, T. Den, Appl. Phys. Lett. 2003, 83, 3347.

[29] N. R. de Tacconi, C. R. Chenthamarakshan, G. Yogeeswaran, A. Watcharenwong, R. S. de Zoysa, N. A. Basit, K. Rajeshwar, J. Phys. Chem. B 2006, 110, 25347.

[30] Y. Li, G. Cheng, L. Zhang, J. Mater. Res. 2000, 15, 2305.

[31] J. Choi, Y. Park, A. Scherer, Nanotechnology 2005, 16, 1655.

[32] J. S. Kim, M. Granstrom, R. H. Friend, N. Johansson, W. R. Salaneck, R. Daik, W. J. Feast, F. Cacialli, J. Appl. Phys. 1998, 84, 6859.

[33] H. B. Michaelson, J. Appl. Phys. 1977, 48, 4729.

[34] K. Mizuno, M. Izaki, T. Shinagawa, M. Chigane, K. Murase, M. Inaba, A. Tasaka, Y. Awakura, Trans. Mater. Res. Soc. Jpn. 2004, 29, 2261. 